\title{
Review
}

Neuro

epidemiology

\section{Incidence and Risk Profile of Dementia in the Regions of Middle East and North Africa}

\author{
Devender Bhalla ${ }^{a} b \quad$ Elham Lotfalinezhad ${ }^{c}$ Fatemah Amini ${ }^{c}$
}

Mohsen Salmannejad $^{d}$ Vahid Reza Borhani Nezhad $^{\mathrm{e}}$

Seyedeh Fatemeh Rezai Kooshalshah ${ }^{f}$ Ahmed Delbari $^{c}$

Reza Fadayevatan ${ }^{g}$ Irmansyah $^{\text {h }}$ Abdalla Abdelrahman ${ }^{\text {i }}$

Nanda Kumar Bhattaj Kurosh Gharagozlik

\begin{abstract}
${ }^{a}$ Iranian Epilepsy Association, Tehran, Iran; bepal Interest Group of Epilepsy and Neurology, Kathmandu, Nepal; ${ }^{c}$ Research Center on Aging, University of Social Welfare and Rehabilitation Sciences, Tehran, Iran; ${ }^{d}$ Research Center

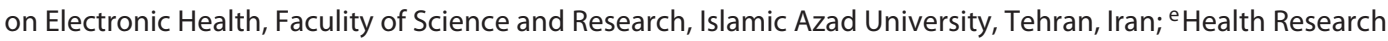
Center of Social Determinants, Institute for Future Studies in Health, Kerman University of Medical Sciences, Kerman, Iran; ${ }^{f}$ Faculty of Medical Sciences, Tarbiat Modares University, Tehran, Iran; ${ }^{9}$ Department of Aging, University of Social Welfare and Rehabilitation Sciences, Tehran, Iran; ${ }^{\mathrm{h}}$ Marzoeki Mahdi Hospital, Bogor, Indonesia;

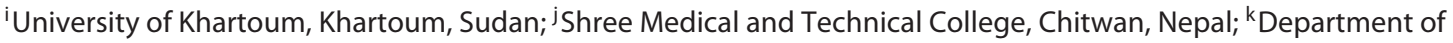
Neurology, Loghman Hakim Hospital, Shahid Beheshti University of Medical Sciences, Tehran, Iran
\end{abstract}

\section{Keywords}

Arab - Dementia · Epidemiology · Incidence · Middle East · North Africa

\footnotetext{
Abstract

Background: The risk of dementia is reported as "epidemic" and "looming" over the Middle East and North Africa (MENA) region. For this, we performed a multi-language review and feasible analysis on the incidence of dementia to offer apt conclusions. Methods: Totally, 3 databases (Magiran, Scientific Information Database, and PubMed) and 1 non-database source (Google) were searched in French, English, and
}

Persian by using specific keywords and their combinations. All searches were independent and had no restriction for the year or type of publication. We also calculated cumulative incidence of dementia for Egypt and Israel-Palestine from relevant prevalence estimates by using standard formula. Results: Little information on incidence was available, sparing Israel (2.4/100,000/year; pre-senile). Ten (48.0\%) countries had none-to-little information (of any kind) on dementia, indicating considerable awareness deficit in this region. Cumulative incidence of dementia in Egypt and Israel-Palestine was $2.7 \%$ over 20 years (55 new cases) and 14.7\% (130 new cases) over 6 years, respectively. In Lebanon, cumulative incidence was $7.5 \%$ over 20 years. Data looked across de-

\section{KARGER}

(c) 2018 S. Karger AG, Basel

E-Mail karger@karger.com

www.karger.com/ned
Dr. Devender Bhalla

Tropical Unit

Nepal Interest Group of Epilepsy and Neurology (NIGEN)

Kathmandu (Nepal) 
mentia-related factors (i.e., fertility rate, polygamy, violence, hypovitaminosis $D$, diabetes, hypertension, life expectancy, age structure) did not seem to support epidemic proportions of dementia for MENA. Conclusions: MENA is youthful and dementia here is neither likely to be an epidemic nor looming over. The only possible exception might be Arab pocket in Israel. To us, previous attributions on dementia do not seem to be based on the realities of this region and, therefore, may prevent pragmatic addressal of dementia. Lastly, values-based collaborations are invited to jointly fill the awareness deficit in a unique low-cost manner.

(c) 2018 S. Karger AG, Basel

\section{Introduction}

Dementia is a broad term for a chronic progressive neurological syndrome, of various stages and forms, that may encompass a set of symptoms related to the domains of memory, communication and language, attention, reasoning, and visual perception, It may be referred as a disease of natural importance among elderly, thus implying its relevance for all populations and geographical regions. Although dementia is important, the references to dementia in the case of Middle East and North Africa (MENA) regions have been seen to have sensational overtones, such as dementia being epidemic [1-3] or huge dementia risk looming over the region [4-6] etc. This may or may not be true but based on previous reports, we believe that such conclusions might be over-the-top since these seem to have been provided based on scant or external data $[5,7,8]$. Thus, continuing with our vision of establishing a reliable neurological research profile and international positive presence for these 2 regions, and with an objective to examine the validity of this looming risk of dementia over MENA, we performed a review of existing local data on the incidence of dementia, and any feasible analysis, for MENA. The authors are not aware of any previous efforts to evaluate the incidence of dementia in-principle for these 2 regions. Here, incidence data is most appropriate since it provides information on the risk-related aspect of dementia.

\section{Methods}

MENA is a unique less-understood less-addressed non-English speaking diverse region, (Fig. 1) [9]. Many of its characteristics across religious practices, dietary aspects, ethnic aspects, political interests, family and social practices, demographic aspects, etc., may have a unique impact on the epidemiology of dementia [9-
11]. Besides this, several MENA countries principally speak French, which might be one of the reasons for having scant data (and perspective) on dementia from this region previously $[5,7]$.

We searched published population-based incidence literature on dementia (of any kind) individually for each MENA country, published either in French, Persian, or English. The search was performed on PubMed (principal, English), Magiran, and Scientific Information Database (SID; secondary, Persian) [12], as well as a free search on 10 pages of Google (French) each time [13]. We used dementia along with the name of each individual MENA country to obtain maximum possible titles during result. One keyword incidence was added for major countries (namely Egypt, Iran, Israel, Jordan, Saudi Arabia) to make search outcome more specific and reduce the number of unrelated titles. Earlier, it was shown that the choice of either a broad or narrow keyword has little impact on the suitability of results obtained during search [13]. All our searches were independent and had no restriction about the year or type of publication. All individual results were required to be population-based (or representative of whole general population in any other manner) and should have had basic methodological details. Those without abstract, not populationbased, experimental studies, without required estimate, addressing specific situations (or populations) or miscellaneously out-of-topics, clinical trials, case reports, ethno-cultural profiles, genetic evaluations, and samples of unrepresentative hospital/care-centers were excluded. In addition, authors were personally contacted in order to obtain references and/or full text of published abstracts. Wadi Ara was considered as Israel-Palestine.

Apart from incidence, suitable literature was free-searched on various aspects of dementia to support (or reject) possible reasons behind epidemic risk of dementia in MENA. These aspects included sociodemographic aspects (age profile, life expectancy, polygamy, fertility rate, migration, conflict, and violence), disease condition (severity of dementia vis-à-vis age), and risk factors (smoking, hypertension, diabetes, hypovitaminosis D).

Additionally, in case of insufficient incidence information for 2 other MENA countries, Egypt $[14,15]$ and Israel-Palestine [16, 17], cumulative incidence was estimated by using 2 (earliest-tolatest) prevalence surveys [18] of the same nature, that is, same population and methodological details as much as feasible (Bhalla, unpubl. data). Similar approach was adopted for Lebanon [19]. The mathematical formula used for this cumulative incidence was (and this does not take into account individual person time of observation) the following:

Cumulative incidence $=(n) /(\mathrm{N}) * 100$,

where $(n)$ is the number of new subjects in a specified period, and $(\mathrm{N})$ is the total number of subjects (at risk) in the study population, at the beginning.

\section{Definitions}

MENA does not have any uniform definition. MENA, for this work, was defined as " 21 sovereign states and territories including Iran" [20]. Even if this may not be explicitly visible, by definition, dementia is a chronic progressive syndrome among the elderly (65 years and above), of various forms and stages, with a deterioration of cognitive function beyond what might be expected from normal aging process. So, it may have symptoms related to the domains of memory, communication and language, attention, reasoning, and 
Fig. 1. Map of Middle East and North Africa regions. WS, Western Sahara.

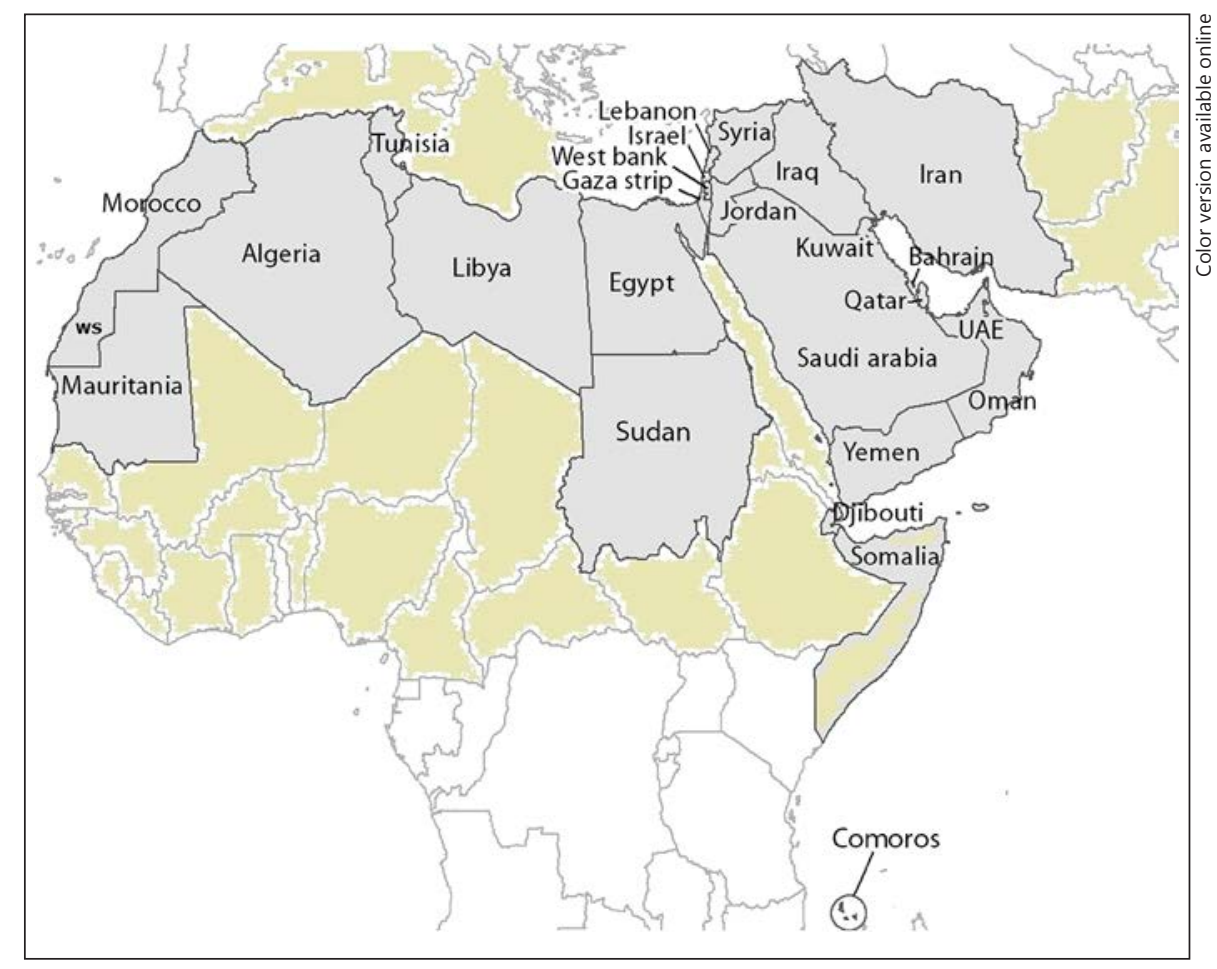

visual perception. An individual's consciousness is not affected. The diagnosis has been, and remains, purely clinical, most commonly based on the Diagnostic and Statistical Manual of Mental Disorders, 4th edition, text revised criteria [21]. This implies the following:

1. Interference with the ability to function independently in usual activities

2. Decline, from prior levels, of functioning and performance

3. Unexplained delirium and major psychiatric disorders

4. Cognitive impairment

- Impaired ability to acquire and remember new information

- Impaired reasoning and handling of complex tasks, and poor judgment

- Impaired visuo-spatial abilities

- Impaired language functions

- Change in personality and behavior

In this post-hoc analysis, the dementia was to be diagnosed (and typed) as per standard practices, that is, clinically or algorithm based but was to be individually noted, segregated, and statistically tested if available data had to allow. Individual definitions/diagnostic criteria that were used for determining the presence of dementia (of any type) was noted, wherever feasible.

\section{Results}

\section{Overall Scope of Any Kind of Data on Dementia}

Overall, 3 countries (14.2\%), that is, Mauritania, Syria, and Western Sahara had no available data (of any kind) on dementia. Seven (33.3\%) other countries had only a fraction of data (of any kind) on dementia: $\operatorname{Morocco}(n=$ $20)$, Iraq $(n=18)$, Algeria $(n=18)$, Kuwait $(n=18)$, UAE $(n=14)$, Bahrain $(n=4)$, and Yemen $(n=2)$. This, in other words, means that 10 countries $(42.0 \%)$ may not seem to conduct dementia as their priority.

In summary, of 74 citations (and abstracts) from Magiran database, none were found to be suitable. From SID, 2 of 27 citations (and abstracts) were preliminarily kept for repeat look and rest were discarded. From PubMed, of 844 citations (and abstracts), 72 were preliminarily kept for repeat look and rest were discarded. From Google, no additional citations were obtained. Of 74 (72 from PubMed and 2 from SID), 6 were kept for deriving direct data on incidence and also on cumulative incidence, and rest were discarded (Fig. 2).

\section{Annual Reported Incidence and Cumulative Incidence of Dementia}

As listed in Table 1, for Israel, the annual incidence of dementia (pre-senile dementia) was found to be $2.4 / 100,000$. Whereas, for Egypt, over a period of 20 years (1994-2014), a total of 55 new cases of dementia (of all types) had occurred and cumulative incidence was therefore estimated to be $2.7 \%$ (or 2,700 per 100,000) over 20 years' period. Similarly for Israel-Palestine (2003-2009), a total of 130 new cases of dementia (of all types) had oc- 


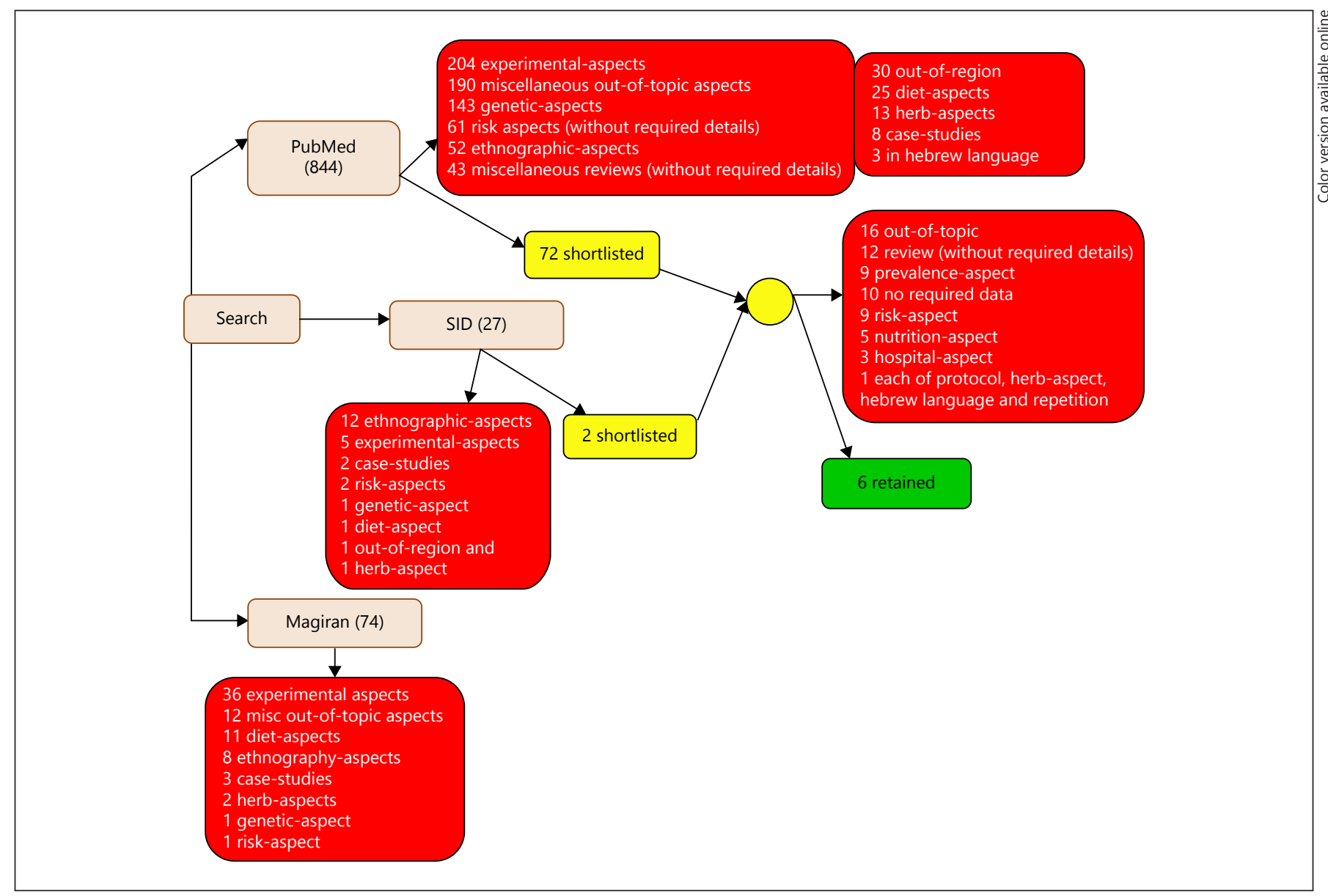

Fig. 2. Flow chart of search for incidence of dementia.

Table 1. Information on the incidence of dementia in the Middle East and North Africa

\begin{tabular}{lllllll}
\hline Country & Year & Age, years & U-R & I/100,000 & Side remarks & Source \\
\hline Israel [68] & 1974 & $40-60$ & B & 2.4 & $\begin{array}{l}\text { National register of all health facilities } \\
\text { nationwide; presenile Alzheimer alone }\end{array}$ & G, P \\
\hline Lebanon [19] & 2012 & $65+$ & B & 7,500 & Cumulative over 20 years (2012-2032) & G, P \\
\hline Egypt [14, 15] & 1994 & $60+$ & U & 2,700 & Cumulative over 20 years (1994-2014) & G, P \\
\hline Israel-Palestine [16, 17] & 2003 & $65+$ & R & 14,700 & Cumulative over 6 years (2003-2009) & G, P \\
\hline
\end{tabular}

G, Google; I, incidence/100,000; IP, Israel-Palestine; P, PubMed; U-R, urban-rural setting.

curred and cumulative incidence of dementia was therefore estimated to be $14.7 \%$ (or 14,700 per 100,000) over 6 years' period. For Lebanon, over a period of 20 years, cumulative incidence of dementia (of all types) was estimated to be $7.5 \%$ (or 7,500 per 100,000). No further and pooled analyses were possible.

Dementia in MENA

\section{Discussion}

This work was performed to bring reliable derivations to dementia (of any kind), which we succeeded by bridging certain awareness-deficit as against previous efforts $[4,5,8,22]$ (Table 1 ). Some had [23] previously raised the 
Table 2. Percentage of endogamy and aged (65+ years) population in the general populations of Middle East and North Africa

\begin{tabular}{llllll}
\hline Country & Percentage & Aged, $\%$ & Country & Percentage & Aged, \% \\
\hline Sudan & 57.0 & 3.3 & Qatar & 30.0 & 1.4 \\
Mauritania & 40.0 & 3.8 & Kuwait & 30.0 & 1.8 \\
Tunisia & 36.0 & 7.3 & Algeria & 27.0 & 5.6 \\
Saudi Arabia & 36.0 & 2.8 & Egypt & 25.0 & 4.3 \\
Syria & 35.0 & 3.8 & Morocco & 25.0 & 4.1 \\
Jordan & 33.0 & 3.4 & UAE & 25.0 & 0.9 \\
Oman & 33.0 & 1.5 & Iran & 25.0 & 5.5 \\
Yemen & 31.0 & 2.6 & Bahrain & 23.0 & 2.2 \\
Western Sahara & NA & 2.3 & Djibouti & NA & 3.3 \\
Somalia & NA & 3.0 & Iraq & NA & 2.9 \\
Libya & NA & 4.0 & Israel & NA & 10.5 \\
Palestine & NA & 3.8 & xx & xx & xx \\
\hline
\end{tabular}

NA, not available.

issue of having unmet needs on dementia in this region but that was for Arabs in Israel, which our work also supports (Table 1). Others had called dementia as epidemic [1-5], which we have not observed anywhere through this comprehensive local work. We therefore were correct to believe that previous regional conclusions about looming risk of dementia in MENA might just be an over-assumption, as additionally shown below.

\section{Proportion of Aged Population in the Countries}

Dementia concerns aged individuals, that is, beyond 65 years of age to start with. In contrast, MENA has a youth bulge; for instance, nearly 1 in 5 people is a youth (15-24 years) in this region [24] although this is different for different countries (Table 2). At least $75 \%$ of Egyptian population is less than 25 years of age, thus making it one of the most youthful populations in the world. This seems to support our low cumulative incidence of dementia in Egypt (Table 1). Similar scenarios are noted in other MENA countries where only a minor fraction of their population is aged; for example, only $0.9 \%$ of the UAE population is over 65 years of age with similar pictures in Qatar, Saudi Arabia, etc. [25]. In case of Palestine, only $4.4 \%$ of the population is $\geq 60$ years of age [26].

\section{Life Expectancy At-Birth and Eligibility of Being At-Risk of Dementia}

Beside the risk of dementia being age specific, it rises exponentially to become substantial only beyond a certain age [27]. So, if we look at the life expectancy of indi- vidual MENA countries, some do not even reach (or remain close-by) 65 years, that is, the minimum eligibility to be called as being at-risk of dementia. For instance, 54.3 years in Western Sahara, 59 years in Iraq, 63 years in Yemen, 65 years in Egypt, 68 years in Syria, etc. This life expectancy at birth may reduce further on as an individual goes on living his/her life due to endogenous or exogenous (population or individual specific) factors, such as infections, other disease conditions, etc. This can be observed from 2 MENA countries, UAE and Qatar, where both have about $1.0 \%$ as the aged population yet the prevalence of dementia in Qatar [28] is 30.5\% of that of UAE [29]. The only contrast seemed to be Israel (and Lebanon) which has the highest life expectancy ( $>82$ years) than all other MENA countries, which is also a country with highest prevalence of dementia [30]. This may partly support our relatively higher cumulative incidence of dementia in Israel-Palestine area (i.e., Arab area), which matches the observations made by others in Israel $[23,31]$. This high risk of dementia here is suggested to be genetic (due to endogamy) in origin [32], even though endogamy is reportedly high in almost all MENA countries [33] (Table 2). Others in Israel consider dementia as an epidemic [6] and report particular risk profile for ethnic groups [34, $35]$ and particular risk factors $[36,37]$.

\section{Sociodemographic Factors (Fertility, Polygamy)}

Dementia-relevant demographic changes in a population can occur through fertility rates and polygamy. MENA has many-fold higher fertility rate (i.e., births per women) than almost all geographic regions except sub- 
Saharan Africa [38]. Some MENA countries like Iraq, Yemen, and Palestine have the highest fertility rates where $>40.0 \%$ populations is actually under 15 years of age [26], which in general contributes toward the youth bulge of MENA region. Besides this, the fertility rates are birth per women which becomes somewhat vague where polygamy (open or silent, done inside or outside of country) is accepted or promoted. Polygamy is prohibited in only one MENA country (i.e., Tunisia) and many marriage types, far more than only one type that we conventionally know, exist in MENA region [39]. Exact reliable data were difficult to generate for each country, but in Qatar, $8.4 \%$ men have polygamous marriage [40] which is $7.0 \%$ in Yemen while Sudan particularly promotes polygamous marriages [39]. In UAE, $32.0 \%$ of all national divorces are due to polygamy [41]. In Saudi Arabia, about half million men are polygamous [42]. These practices may ensure that the region remains young [43].

\section{Migration of Aged Population}

Because of direct colonial relations of some MENA countries with Europe, particularly France, a large proportion of individuals migrate. For instance, in 2008, 1.7 million of those $\geq 65$ years of age migrated to France, of which $61.0 \%$ belonged to Maghreb (49.0\% of Algeria, $35.0 \%$ of Morocco, $16.0 \%$ of Tunisia) [44]. It is important to note that in MENA countries like Algeria or Tunisia, nationality of colonial country (i.e., France) is almost a right and a norm (Bhalla, field data). Thus, it is quite likely that population aging of MENA might also be getting buffered to some extent through such annual migrations.

\section{Demographic Changes Due to Conflict and Violence Situations}

It is often contended that the risk of dementia might be high because of demographic changes that may occur in conflict and violent situations through loss of youth and widowhood [45]. However, in contrast to popular beliefs, it is Latin America which is the most violent region in the world, followed by Africa, and not MENA region/countries [46].

\section{Smoking}

Smoking is a definite habit in MENA, partly as part of their culture, and its rates vary by country [47]. Tobacco use is highest in Lebanon within this region. The odds of developing dementia from smoking is quite modest (1.2 times, 95\% CI 1.0-1.6) in both international [48] and MENA population such as merely 1.1 (95\%
CI 0.5-2.3) times the risk of dementia in Iran [27]. In Qatar, the risk of dementia due to smoking does not seem to exist [49].

\section{Hypertension (Systolic and Diastolic)}

Just like dementia, sensational references have been attributed to hypertension as well for the MENA region, for instance "blood pressure boiling in MENA" [50]. The risk of dementia due to hypertension is also somewhat modest (1.6 times, 95\% CI 1.0-2.7) [51] and even lower if hypertension remains controlled [52]. A closer look at existing scant data reveals correct interpretations with this regard. For instance, in Israel-Palestine, although the odds of developing Alzheimer's from hypertension was reported to be 2.08 (95\% CI 1.18-3.65), there were considerably more women in the Alzheimer group than all other control groups when female gender was reported by themselves to be a strong independent risk factor for Alzheimer [17]. Besides this, in Iran as well the risk of dementia due to hypertension remains modest (1.4 times, 95\% CI 1.0-2.2) [27]. Just like elsewhere, the risk of dementia in MENA may also depend upon the type of hypertension (systolic or diastolic) and whether it is controlled or not [53].

\section{Diabetes (Insulin- and Non-Insulin Dependent)}

Diabetes (both insulin and non-insulin dependent) has been reported to be enormously present in MENA, but in reality there are likely to be only scattered pockets of high prevalence $[54,55]$. Both types of diabetes have been reported to be associated with the risk of dementia, although the odds of developing dementia remain modest again and causal-effect being not necessarily direct or independent [56]. For instance, an analysis of 28 studies showed a relative risk of dementia from insulin-dependent diabetes (IDD) of 1.7 (95\% CI 1.6-1.8) which was lower for Alzheimer (1.5, 95\% CI 1.4-1.7) [57]. The relative risk for vascular dementia was expectedly higher (2.2, 95\% CI 1.9-2.6) but this type makes only a fraction of total dementia population.

Other reviews have reciprocated similarly low risk of dementia from IDD, globally (1.5 times, 95\% CI 1.411.75) [58] and in MENA (1.4 times, 95\% CI 1.20-1.77) [59]. It is also surprisingly noted that the risk of dementia from IDD is reported as being considerably huge yet in the same populations this risk reportedly in exist [60]. This matches somewhat to observation from Iran that shows overweight as a possible protective factor for incidence of dementia in elderly [61]. For non-IDD, there is only a small-to-modest decrease in cognitive performance [62]. 


\section{Hypovitaminosis D and Burqa}

Hypovitaminosis D is another MENA relevant risk factor for dementia [63]. Varying rates of hypovitaminosis $\mathrm{D}$ are reported in most MENA countries although there is only insufficient population-based data to determine reliable estimates on hypovitaminosis D [64]. This dementia risk factor might be particularly relevant among MENA women because of Burqa that might limit their required natural sun exposure. Sun exposure was earlier shown by the last author to have preventive effect against certain neurological disorders [65].

\section{Summary of Key Findings (Primary Outcome}

Measures, Secondary Outcome Measures, Results as

They Relate to a Prior Hypothesis)

The primary outcome measure was the incidence estimate of dementia, of any type. We were able to identify and define such estimates for 4 countries, Israel, Lebanon, Egypt, and Israel-Palestine (Table 1). Another such measure was to find reasons behind epidemic proportion or looming risk of dementia on MENA, against which we systematically provided 9 local evidence. Based on simple mathematical calculations (Table 1), the number of people affected with any dementia are not expected to be of epidemic proportions: 54,637 over 20 years in Lebanon (i.e., roughly 2,731 /year), or 107,145 over 20 years in Egypt (i.e., roughly 5,357/year), or 15,255 over 6 years in Israel-Palestine (i.e., roughly 2,542/year), implying roughly 10,600 incident cases/year. Could this match dementia epidemic looming over 135 million sufferers? [1$3]$. We could not find data on various other outcomes such as by individual type and stage of dementia, etc.

\section{Strengths and Limitations of the Study (Study}

Question, Study Design, Data Collection, Analysis, and Interpretation)

Our work had addressed the suitable question that is of relevant to all. For instance, public agencies have particularly recommended in The Declaration of Santiago on Neurological Disorders, "the need for promotion of research and education as well as publication of detailed public health assessments and development of national plans" [66]. Our work advances this recommendation for MENA region, where there is a definite need, as shown widely above. We had included surveys with standard definitions and representative designs, and data were systematically searched, collected, analyzed, and interpreted. This was done in several languages, including Persian and French, which is the official and the only language in a certain part of MENA. This might be one of the reasons for having had scant data (and perspective) on dementia from this region previously $[5,7]$. So, there was a definite need that now seems to have been addressed to certain extent. We had also looked through databases and nondatabase sources that may be added representatively [13].

The limitations of work may include that we did not search in Arabic. Our work was post-hoc, implying we had to restrict ourselves to the details and criteria used by others, and not to define or correct them upfront as new. Despite efforts, we could not find much direct data for many countries but we have provided aspects related to the risk of dementia for each of them. We did not take into account statistical influence of definition of dementias, diagnostic methods adopted, many other risk factors of dementias (including Parkinson's disease and cardiovascular conditions), rural-urban environment, refugee status, forms of dementias, quality of healthcare system difference between countries, and local social practices, etc. For instance, the healthcare system in countries such as Israel or Lebanon is better placed than other countries, or in Egypt, the patients may not come out or be found since dementia is considered as a natural phenomenon not requiring any treatment or health service. Ideally, a diagnostic assessment on dementia should include multidomain cognitive testing, disability assessment, clinical interview, and informant interview. This way only $43 \%$ of all worldwide studies (i.e., include most western developed countries) may succeed in meeting the inclusion criteria [67]. Where MENA may lie in this? Having very strict criteria is in fact not very practical and would hinder any (and all) research which is against the recommendations and scientific needs stated above.

The readers may quickly argue that dementia is underdiagnosed but this should not be a limitation to our work since we provided 9 evidence-based reasons to support the risk (i.e., incidence, not prevalence) of dementia not being the way it is often projected to be in most of MENA.

\section{Interpretation and Implications in the Context of the Totality of Evidence}

In totality, we interpret that direct local evidencebased data of dementias were insufficient to have provided regional conclusions based on them. But, as strongly shown above, plenty of other evidence-based local data is provided to question the epidemicity of dementias. To us, the only country seeming to be at clear risk of dementias would be the Arab pockets of Israel (i.e., Palestine). Despite this, in current situation, the number of people affected with any dementia is expected to be not of epidemic proportions (assumed linear distribution): 54,637 
over 20 years in Lebanon, 107,145 over 20 years in Egypt, 15,255 over 6 years in Israel-Palestine (i.e., 10,600 incident cases/year). The research has been shown elsewhere by the first author as one of the most effective tools for bringing direct changes in local structures and stakeholders, something that needs global acceptance and local attention.

\section{Controversies Raised by This Study}

The principal objective of this work was not to raise any controversy or reduce public health significance of dementias, but to remove sensational over-tones and address those regions that have since been rejected. This is essential for a rational addressal of such complex disease conditions and advancement through participation. Similar work was performed before by the first author for dissipating erroneous conclusions and sensational impressions on epilepsy in Africa, Latin America, The Caribbean, and Asia. The only controversy that we deliberately raise is a request to ask ourselves on such prior conclusions even when local evidence-based data may state otherwise.

\section{Future Research Directions}

The future direction should be to principally determine epidemiological parameters of dementias in these silent countries. Similar works should also be jointly performed for other regions and disease conditions to provide (a) appropriate conclusions and (b) to dissipate unnecessary sensation and negativity around them. Neuro- logical disorders have consistently been projected through their negativities (e.g., stigmatizing) instead of working through their positive image (e.g., ready solutions available). There is also a need to look toward these regions as well. Many of these countries are so wealthy and have ready healthcare delivery structures in such a manner that may easily raise representative data on any of the desired disorders.

\section{Conclusions}

According to us, dementia neither seems to be an epidemic nor is its risk looming over MENA. A possible exception in terms of Israel might exist because of high life expectancy and because of Arab pockets. Previous regional derivations seem unrealistic and do not seem to be based on the realities of this region across sociodemographic aspects, disease condition, or risk factors that we included. There is also a need to project neurological disorders through their positive image rather than through their negativity, as has always been the habit since long. Finally, values-based collaborations are invited to jointly perform field work on dementia in this region in a unique low-cost manner.

\section{Disclosure Statement}

The authors declare no conflicts of interest.

\section{References}

1 Kelland K: Dementia Epidemic Looms with 135 Million Sufferers Seen by 2050. London, Reuters, 2013.

$\checkmark 2$ Treves TA, Korczyn AD: Modeling the dementia epidemic. CNS Neurosci Ther 2012; 18:175-181

-3 Larson EB, Yaffe K, Langa KM: New insights into the dementia epidemic. N Engl J Med 2013;369:2275-2277.

4 Parry J, Weiyuan C: Looming dementia epidemic in Asia. Bull World Health Organ 2011; 89:166-167.

5 Rizzi L, Rosset I, Roriz-Cruz M: Global epidemiology of dementia: Alzheimer's and vascular types. Biomed Res Int 2014;2014:908915.

6 Korczyn AD, Vakhapova V: The prevention of the dementia epidemic. J Neurol Sci 2007; 257:2-4.

7 Wu YT, Matthews FE, Brayne C: Dementia: time trends and policy responses. Maturitas 2014;79:191-195.
-8 Fiest KM, Roberts JI, Maxwell CJ, et al: The prevalence and incidence of dementia due to Alzheimer's disease: a systematic review and meta-analysis. Can J Neurol Sci 2016;43(suppl 1):S51-S82.

-9 Hajjar RR, Atli T, Al-Mandhari Z, et al: Prevalence of aging population in the Middle East and its implications on cancer incidence and care. Ann Oncol 2013;24(suppl 7):vii11vii24.

10 Bhalla D, Lotfalinezhad E: A short perspective on the risk profile of epilepsy in Iran. J Neurol 2016;1:3-4.

11 Ghanbari MR, Lotfalinezhad E, Lotfalinezhad $\mathrm{E}$, et al: A representative survey of knowledge, use, perceived benefits, barriers, and risks of select herbal drugs among female students in Gorgan City (Northeast Iran). J Evid Based Complementary Altern Med 2016;22:227-231.

12 Sadeghi H: Recall and precision of iranmedex, magiran and sid (scientific information data- base) databases for retrieval of scholarly information in the field of pharmacy. Healt Info Manag 2014;11:435-442.

13 Bhalla D, Lotfalinezhad E, Timalsina U, et al: A comprehensive review of epilepsy in the Arab World. Seizure 2016;34:54-59.

14 Khedr E, Fawi G, Abbas MA, et al: Prevalence of mild cognitive impairment and dementia among the elderly population of Qena Governorate, Upper Egypt: a community-based study. J Alzheimers Dis 2015;45: 117-126.

15 Farrag A, Farwiz HM, Khedr EH, et al: Prevalence of Alzheimer's disease and other dementing disorders: Assiut-Upper Egypt study. Dement Geriatr Cogn Disord 1998;9: 323-328.

16 Inzelberg R, Afgin AE, Massarwa M, et al: Prayer at midlife is associated with reduced risk of cognitive decline in Arabic women. Curr Alzheimer Res 2013;10:340-346. 
-17 Israeli-Korn SD, Masarwa M, Schechtman E, et al: Hypertension increases the probability of Alzheimer's disease and of mild cognitive impairment in an Arab community in northern Israel. Neuroepidemiology 2010;34:99105.

18 Salvarani F, Nichelatti M, Montomoli C: Recovering incidence from repeated measures of prevalence: the case of urinary tract infections. J Clin Monit Comput 2010;24:269-277.

19 Bassil N, Mollaei C: Alzheimer's dementia: a brief review. J Med Liban 2012;60:192-199.

20 UNHCR: Middle East and North Africa. Geneva, UN, 2015. http://www.unhcr.org/ pages/4a02db416.html (cited April 15, 2015).

21 American Psychiatric Association: Diagnostic and Statistical Manual of Mental Disorders. Washington, American Psychiatric Association, 2000

22 Prince M, Bryce R, Albanese E, et al: The global prevalence of dementia: a systematic review and metaanalysis. Alzheimers Dement 2013; 9:63-75.e2.

23 Werner P, Friedland RP, Inzelberg R: Alzheimer's disease and the elderly in Israel: are we paying enough attention to the topic in the Arab population? Am J Alzheimers Dis Other Demen 2015;30:448-453.

24 Assaad R, Roudi-Fahimi F: Youth in the Middle East and North Africa: Demographic Opportunity or Challenge? Cairo, PRB, 2007.

25 World Bank: Population Statistics. Washington, World Bank, 2015.

26 Palestine Central Bureau of Statistics. Ramallah, PCBS, 2015.

27 Sharifi F, Fakhrzadeh H, Varmaghani M, et al: Prevalence of dementia and associated factors among older adults in Iran: national elderly health survey (NEHS). Arch Iran Med 2016; 19:838-844.

28 Ghuloum S, Bener A, Abou-Saleh MT: Prevalence of mental disorders in adult population attending primary health care setting in Qatari population. J Pak Med Assoc 2011;61: 216-221.

29 Ghubash R, El-Rufaie O, Zoubeidi T, et al: Profile of mental disorders among the elderly United Arab Emirates population: sociodemographic correlates. Int J Geriatr Psychiatry 2004; 19:344-351.

-30 Feldman H, Clarfield AM, Brodsky J, et al: An estimate of the prevalence of dementia among residents of long-term care geriatric institutions in the Jerusalem area. Int Psychogeriatr 2006; 18:643-652.

-31 Bowirrat A, Friedland RP, Chapman J, et al: The very high prevalence of $\mathrm{AD}$ in an Arab population is not explained by APOE epsilon4 allele frequency. Neurology 2000;55:731.

32 Farrer LA, Bowirrat A, Friedland RP, et al: Identification of multiple loci for Alzheimer disease in a consanguineous Israeli-Arab community. Hum Mol Genet 2003;12:415422.

33 Courbage Y, Todd E: Arab Family and Transition Crisis. A Convergence of Civilizations: The Transformation of Muslim Societies around the World. New York, Columbia University Press, 2014, pp 29-35.

34 Kahana E, Zilber N, Abraham M: Do Creutzfeldt-Jakob disease patients of Jewish Libyan origin have unique clinical features? Neurology 1991;41:1390-1392.

35 Bowirrat A, Friedland RP, Chapman J, et al: The very high prevalence of $A D$ in an Arab population is not explained by APOE epsilon4 allele frequency. Neurology 2000;55: 731.

36 Barak Y, Cohen A: Characterizing the elderly homeless: a 10-year study in Israel. Arch Gerontol Geriatr 2003;37:147-155.

37 Ben-Hur T, Wolff E, River Y: [Thiamin deficiency is common in Israel]. Harefuah 1992; 123:382-384, 436, 435.

38 World Bank: Fertility Rate, Total (Birrths per Women). Washington, World Bank, 2015.

39 Abu-Raddad LJ, Francisca Ayodeji A, Iris S, et al: Chapter 6: general population and HIV; in Bank TW (ed): Characterising the HIV/ AIDS-Epidemic in the Middle East and North Africa. Washington, The World Bank, 2010, pp 65-75.

40 MDPS: Marriage and Divorce in the State of Qatar. Doha, Ministry of Development and Planning Statistics, 2014.

41 Ministry: Polygamy, a Major Cause of Divorce. UAE, Ministry of Labour and Social Affairs, 2005.

42 GAS: Over Half Million Saudi Men Engaged in Polygamy. Saudi Arabia, General Authority of Statistics, 2016.

43 Fakhro M: Gulf women and islamic law; in Yamani M, Allen A (eds): Feminism and Islam: Legal and Literary Perspectives. New York, New York University Press, pp 255270.

44 Ngatcha-Ribert L: Maladie d'alzheimer: cultures, diversités, identités. France, Institut national de la statistique et des études économiques, 2008.

45 Corfield S: Women and Dementia - A Global Challenge. London, Global Alzheimer's \& Dementia Action Alliance, 2017.

46 UNODC: Global Study on Homicide. Vienna, UNODC, 2013

47 Khattab A, Javaid A, Iraqi G, et al: Smoking habits in the Middle East and North Africa: results of the BREATHE study. Respir Med 2012;106(suppl 2):S16-S24.

48 Anstey KJ, von Sanden C, Salim A, et al: Smoking as a risk factor for dementia and cognitive decline: a meta-analysis of prospective studies. Am J Epidemiol 2007; 166:367378.

49 Hamad AI, Ibrahim MA, Sulaiti EM: Dementia in Qatar. Saudi Med J 2004;25:79-82.

50 Baris E, Samah Rabie T, Pande AH: A blood pressure boiling in MENA. Jordan, The World Bank, 2013.

51 Bellew KM, Pigeon JG, Stang PE, et al: Hypertension and the rate of cognitive decline in patients with dementia of the Alzheimer type. Alzheimer Dis Assoc Disord 2004;18:208213.
52 Launer LJ, Hughes T, Yu B, et al: Lowering midlife levels of systolic blood pressure as a public health strategy to reduce late-life dementia: perspective from the Honolulu Heart Program/Honolulu Asia Aging Study. Hypertension 2010;55:1352-1359.

53 Sharifi F, Hedayat M, Fakhrzadeh H, et al: Hypertension and cognitive impairment: Kahrizak Elderly Study. Int J Geront 2011;5:212216.

54 Sherif S, Sumpio BE: Economic development and diabetes prevalence in MENA countries: Egypt and Saudi Arabia comparison. World J Diabetes 2015;6:304-311.

55 Abuyassin B, Laher I: Diabetes epidemic sweeping the Arab world. World J Diabetes 2016;7:165-174.

56 Saedi E, Gheini MR, Faiz F, et al: Diabetes mellitus and cognitive impairments. World J Diabetes 2016;7:412-422.

57 Gudala K, Bansal D, Schifano F, et al: Diabetes mellitus and risk of dementia: A meta-analysis of prospective observational studies. J Diabetes Investig 2013;4:640-650.

58 Vagelatos NT, Eslick GD: Type 2 diabetes as a risk factor for Alzheimer's disease: the confounders, interactions, and neuropathology associated with this relationship. Epidemiol Rev 2013;35:152-160.

59 Hazar N, Seddigh L, Rampisheh Z, et al: Population attributable fraction of modifiable risk factors for Alzheimer disease: a systematic review of systematic reviews. Iran J Neurol 2016;15:164-172.

60 Bowirrat A, Friedland RP, Korczyn AD: Vascular dementia among elderly Arabs in Wadi Ara. J Neurol Sci 2002;203-204:73-76.

61 Ghaderpanahi M, Sharifi F, Fakhrzadeh H, et al: Overweight as a protective factor in dementia incident in elderly residents of Kahrizak charity Foundation aged 80 and older. Iran J Aging 2010;4:49-58.

62 Tonoli C, Heyman E, Roelands B, et al: Type 1 diabetes-associated cognitive decline: a meta-analysis and update of the current literature. J Diabetes 2014;6:499-513.

-63 Littlejohns TJ, Henley WE, Lang IA, et al: Vitamin $\mathrm{D}$ and the risk of dementia and $\mathrm{Al}$ zheimer disease. Neurology 2014;83:920-928.

64 Bassil D, Rahme M, Hoteit M, et al: Hypovitaminosis D in the Middle East and North Africa: Prevalence, risk factors and impact on outcomes. Dermatoendocrinol 2013;5:274298.

65 Dalmay F, Bhalla D, Nicoletti A, et al: Multiple sclerosis and solar exposure before the age of 15 years: case-control study in Cuba, Martinique and Sicily. Mult Scler 2010;16:899-908.

-66 Declaration of Santiago on epilepsy in Latin America. Epilepsia. 2002;43(suppl 6):42.

67 Prince M, Bryce R, Albanese E, et al. The global prevalence of dementia: a systematic review and metaanalysis. Alzheimers Dement 2013; 9:63-75.e2.

68 Treves T, Korczyn AD, Zilber N, et al: Presenile dementia in Israel. Arch Neurol 1986;43: 26-29. 